Article

\title{
Study of the Cu-Ni Productive Suite of the Pechenga Structure on the Russian-Norway Border Zone with the Use of MHD Installation "Khibiny"
}

\author{
Abdulkhai A. Zhamaletdinov ${ }^{1,2}$ \\ 1 Geological Institute, Kola Science Centre, Russian Academy of Sciences, 184209 Apatity, Russia; \\ abd.zham@mail.ru; Tel.: +7-921-169-2104 \\ 2 St. Petersburg Branch of the Institute of Terrestrial Magnetism, Ionosphere and Radio Waves \\ Propagation (SPbB IZMIRAN), 190034 St Petersburg, Russia
}

Received: 28 December 2018; Accepted: 3 February 2019; Published: 8 February 2019

check for updates

\begin{abstract}
The tracing of current-conducting channels of the Pechenga structure from Russian to Norwegian territory was the main task of this research. The study was carried out in the framework of the Soviet-Norwegian cooperation "Northern Region" to estimate the prospects for discovery of $\mathrm{Cu}-\mathrm{Ni}$ deposits in northern Norway. In addition to previous publications of technical character, the emphasis here is on geological description. Experimental measurements have been performed in the field of the "Khibiny" dipole and with the use of DC electrical profiling. The "Khibiny" dipole consists of 160-ton aluminum cable flooded in the Barents Sea bays on opposite sides of the Sredny and Rybachy peninsulas. Measurements were implemented as in the mode of single pulses generated by 80 MW magneto-hydrodynamic (MHD) generator "Khibiny" ("hot" launches) and in the accumulation mode of rectangular current pulses of $0.125 \mathrm{~Hz}$ frequency generated by a $29 \mathrm{~kW}$ car generator ("cold" launches). From results of measurements, it was concluded that the most promising potential for Cu-Ni deposits Pil'gujarvi formation of the Northern wing of the Pechenga structure is rather quickly wedged out in Norway, while the conductive horizons of the Southern part of Pechenga, which have a weak prospect for $\mathrm{Cu}-\mathrm{Ni}$ ores, follow into Norway nearly without a loss of power and integral electrical conductivity.
\end{abstract}

Keywords: Khibiny promising structures; conductive layers; MHD-source "Khibiny"; Pechenga structure; Kola Peninsula

\section{Introduction}

In the early 1970s, a new scientific direction appeared in Russia (former Soviet Union)_the deep electromagnetic soundings on the base of a unique technology-impulsive magnetohydrodynamic (MHD) generators with a power of tens and up to one hundred MegaWatts. The initiator and supervisor of the new geophysical direction was Academician E.P. Velikhov, vice president of the Russian Atomic Energy Institute [1,2]. The need to develop a new direction was determined by the increased requirements for the depth and reliability of geoelectrical research. For a relatively short time, several MHD experiments were performed for the purposes of earthquake prediction (the Garm test site in the Pamirs and the Frunze test site in the Tien Shan), to study the structure of the Earth's crust and to predict ore deposits (the Chelyabinsk test site in the Southern Urals and the Khibiny test site on the Kola Peninsula), to search for oil and gas deposits (Vanavaar test site in Siberia and the Astrakhan test site in the Southern Volga region) and to solve some problems of extra low-frequency (ELF) radio communications $[3,4]$.

Among the noted research projects, the MHD experiment "Khibiny" on the Kola Peninsula, which lasted from 1974 to 1991, was one of the most significant. The task of the Khibiny MHD experiment 
included studying the structure of the Earth's crust and upper mantle up to the depth of 100-150 km, the study of the block structure of the Earth's crust conductivity of the Baltic Shield over aterritory of about 200 thousand square kilometers, the sounding of the seafloor in the adjacent water area of the Barents sea [5]. The study of ore prospective, high conductive structures (current conductive channels) in the Kola Peninsula and in the neighboring countries (Northern Norway and Finland) has been accepted as one promising task of the Khibiny experiment. In this article, the general concepts of theory and methodology of this study are presented. Specific application is presented on the example of volcanogenic-sedimentary high-conductive horizons tracing on the western flank of the Pechenga structure in Norway. The basis for the formulation of the problem was the hypothesis that in the West, in the territory of Northern Norway, the thickness of the Pil'guarvi (so-called "productive") high conductive sulfide and carbon-bearing stratum should increase and with it, the prospects for discovery of copper-nickel deposits.

The Pechenga structure of the Low Proterozoic age consists of Northern and Southern volcanogenic-sedimentary series. The most extensive sedimentary formations are presented by the Pil'gujarvi series in the Northern Pechenga and by the Kallojavr-Porjitash, Bragino and Langvannet-Porojarvi series in the Southern Pechenga [6]. They are similar to each other by composition but different in their Cu-Ni potential [7]. Pil'gujarvi formation (the fourth sedimentary layer of the Northern Pechenga) contains many Cu-Ni deposits (Kaula, Kammikivi, Semiletka, Zhdanovka, etc.), which are linked to differentiated massifs of basic-ultrabasic rocks. Thus, this suite has been called the Productive stratum [8]. In the Southern series of the Pechenga structure with its major Kallojavr-Porjitash, Bragino and Langvannet-Porojarvi formations, on the contrary, differentiated massifs of basic-ultrabasic rocks are nearly absent. Thus, their potentials for $\mathrm{Cu}-\mathrm{Ni}$ ores are fairly low. All sedimentary suites of the Pechenga structure (northern and southern) possess high electric conductivity due to the overabundance of sulfide-carbonaceous schists and phyllites that contain electronically conductive minerals, such as pyrite, pyrrhotite, graphite and sometimes titan magnetite. In the field of the MHD-installation "Khibiny", the Northern and Southern series of the Pechenga structure reveal themselves as two individuals (insulated) current-conducting channels [9].

The "Northern Region" project headed by Brian Sturt (Norway) and Felix Mitrofanov (Russia) has aimed at thetracing of sedimentary volcanic formations of the Pechenga structure with the purpose of investigating perspectives for $\mathrm{Cu}-\mathrm{Ni}$ deposits further to the West, in the Norwegian territory. The hypothesis on the possible increase of the Productive layer in the Northern Norway area has been accepted on the base of project "Northern Region". As a solution, the study of high electrically conductive structures was included in this project. Experimental measurements have been performed in the field of "Khibiny" dipole and with the use of DC electrical profiling. The "Khibiny" dipole consists of 160-ton aluminum cable flooded in the Barents Sea bays on opposite sides of the Sredny and Rybachy peninsulas. Measurements were implemented as in the mode of single pulses generated by the $80 \mathrm{MW}$ magneto-hydrodynamic (MHD) generator "Khibiny" in the accumulation mode of rectangular current pulses of $0.125 \mathrm{~Hz}$ frequency generated by $29 \mathrm{~kW}$ car generator. In addition to previous publications of technical character $[10,11]$, the emphasis here is on geological description.

The first section of this paper briefly highlights the parameters and techniques of "hot" and "cold" launches. The second section describes the physical model and technique of data processing that has been taken as the basis to study current-conducting channels. The third section provides analyses of the results obtained. The final part is devoted to a discussion and summary.

\section{Technique of Sounding with MHD-Installation "Khibiny"}

Technique and main results of the deep electromagnetic soundings with the use of the "Khibiny" MHD-source are described in numerous scientific and educational publications. Below, only a brief description of the technique necessary to understand the results is presented. Detailed data can be gathered from [2-5]. 


\section{1. "Hot" Launches}

The summary diagram illustrating the MHD source "Khibiny" is shown in Figure 1. The main peculiarity of the "Khibiny" source is a dual MHD generator of $80 \mathrm{MW}$ power (Figure 1e) and transmitting antenna made of aluminum cable of $7.5 \mathrm{~km}$ length and 160 tons weight that has been immersed in the sea bays on the opposite sides of the isthmus between the Kola and Srednypeninsulas (Figure 1a). A schematic diagram of the operation of one of two generators is given in Figure $1 \mathrm{~b}$. The MHD-generator works based on the Faraday's law [9]. In a plasma generator (Figure 1b-1), which is a capsule with powder fuel of $700 \mathrm{~kg}$ weight, the conductive "cold" plasma is produced by fuel combustion with some cesium added. The conductive plasma flows into an MHD-channel with a velocity of $3 \mathrm{~km} / \mathrm{s}$ (Figure $1 \mathrm{~b}-2$ ).

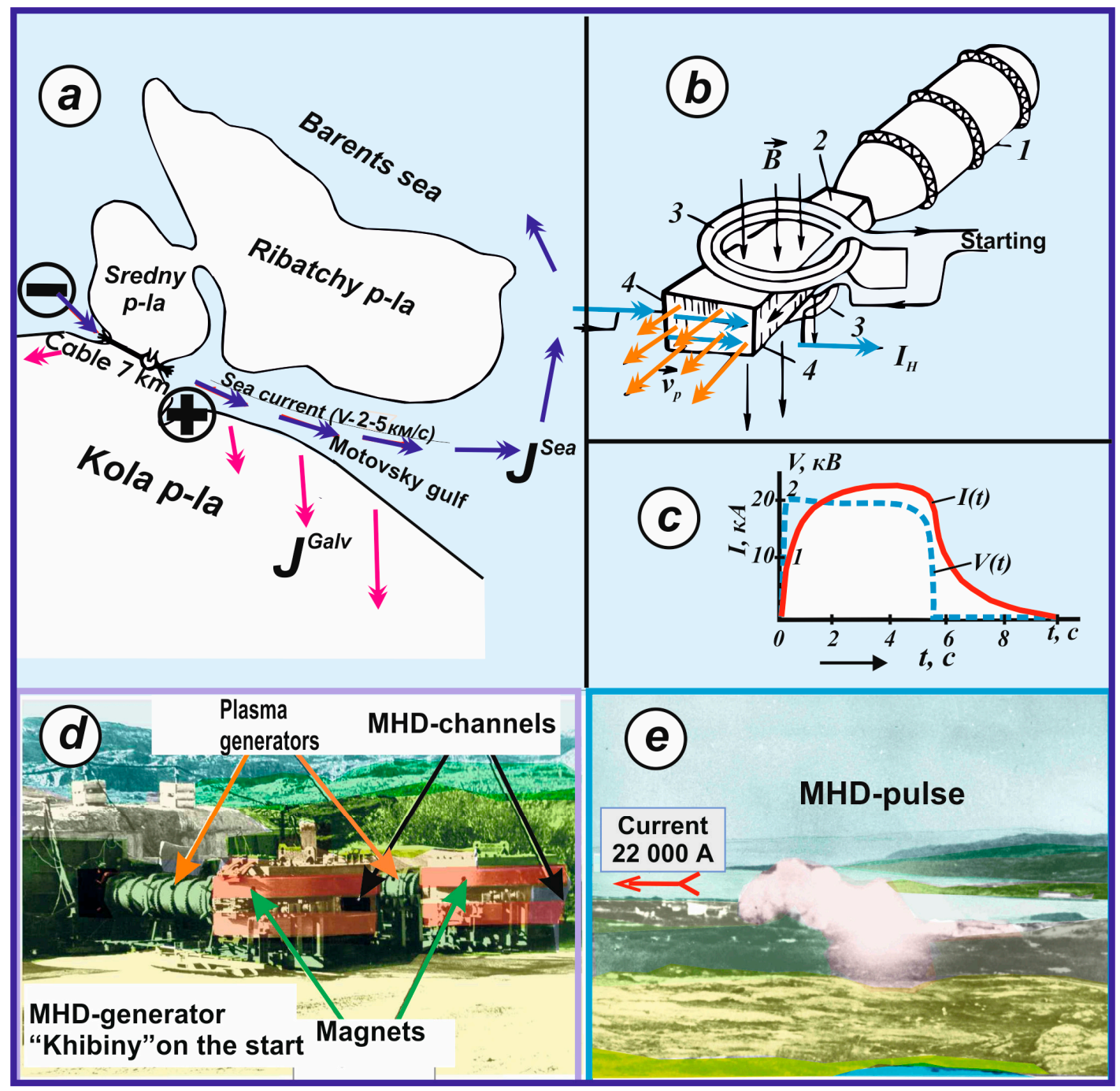

Figure 1. The MHD-installation "Khibiny". (a) Location of 160 ton cable of $7 \mathrm{~km}$ length and currents in the sea, $J^{\text {sea }}$ and currents in the ground, $J^{\text {galv }}$; (b) principal scheme of pulse MHD-generator "Khibiny"; (c) voltage and current intensity in the output of MHD generator "Khibiny"; (d) the view of the dual MHD generator "Khibiny"in the working position; (e) the gas outbreak that appeared from the MHD pulse producing the current of $22 \mathrm{kA}$ in the Motovsky sea gulf.

The MHD-channel is placed between two coreless magnets (Figure 1b-3). Force $\vec{F}$, induced by plasma flow, is exerted perpendicularly both towards the direction of the conductor's movement and towards the direction of the magnetic induction vector $\vec{B}$. Force $\vec{F}$ pushes charges from the conductor 
(the Hall effect). The force $\vec{F}$ of interaction between charges and the magnetic field can be found by the Lorentz equation as: $\vec{F}=\vec{v} \cdot Q \cdot \vec{B}$, where $\vec{v}[\mathrm{~m} / \mathrm{s}]$-is velocity of conductor's movement, $Q[A \cdot m]$ 一charge in Coulomb, $\vec{F}\left[\frac{V \cdot s \cdot A}{m}\right]$ 一the force in Newton, $\vec{B}\left[\frac{V \cdot s}{m^{2}}\right]$-magnetic induction vector in Tesla.

The current flows through conductive sidewalls of MHD-channels and passes to an external load, by the cable to the sea (Figure 1b-4). One from two MHD-generators of the "Khibiny" installation works in the auto-excitation mode. It induces the current for the feeding of its own electric magnets. Half of the current is channeled to electric magnets of another generator that sends all of the current to a power cable connecting opposite gulfs of the Sredny and Rybachypeninsulas (Figure 1a). The maximum voltage is $2 \mathrm{kV}$, and the maximum current is $22 \mathrm{kA}$. Therefore, the maximum power exerted from the MHD generator is about $44 \mathrm{MW}$. The launch of the MHD-generator is followed by a huge gas outbreak, approximately $500 \mathrm{~m}$, marked on Figure 1e. Figure 1c shows that the current in the external load increases gradually despite a rectangular voltage waveform. This is due to a high inductance of the circuit (up to $70 \mathrm{mHn}$ ). The current reaches its maximum value ("ceiling") in 1-2 s after switching on the rectangular pulse of voltage.

The current passes from West to the East since the positive charge is always supplied to the Motovsky Gulf, where the eastern end of the cable is flooded and grounded (Figure 1a). The current diffuses from the coastline towards the sea. The diffusion parameter of the electromagnetic field follows from the first two Maxwell equations and has the form $M=\frac{1}{\sigma \cdot \mu_{0}},\left[\frac{m^{2}}{\mathrm{~s}}\right]$, where $\sigma\left[\frac{1}{\Omega \cdot m}\right]$ - specific conductivity and $\mu_{0}=4 \pi \cdot 10^{-7}\left[\frac{V \cdot s}{A \cdot m}\right]$-vacuum permeability. The sea can be represented as a thin S-film with thefixed one coordinate- the depth of the sea, $h$. In this case, the expression for the diffusion rate of the electromagnetic field will take the form $v=\frac{1}{\sigma \cdot \mu_{0} \cdot h},\left[\frac{\mathrm{m}}{\mathrm{s}}\right]=\frac{800}{\mathrm{~S}},\left[\frac{\mathrm{km}}{\mathrm{s}}\right]$, where $S=\sigma \cdot h,[S m]$ is longitudinal conductivity in siemences. In the coastal zone, the sea depth is in the range of 50-100 m. The longitudinal conductivity of the sea is in the range of 150-300 Sm. From here, the average speed of current diffusion in the sea is in the range of $3-5 \mathrm{~km} / \mathrm{s}$. The drifting currents produce current loops $\left(J^{\text {sea }}\right)$ around the Sredny and Rybachy peninsulas, creating induction-type $\left(H^{\text {ind }}\right)$ magnetic fields. Some current (about 20\%) leaks through the sea bottom into the Earth crust by the galvanic way ( $\left(^{g a l v}\right.$ ) and produces galvanic-type magnetic fields $\left(H^{g a l v}\right)$. The ratio between the currents, penetrating into the earth by galvanic way, and the currents diffusing into the sea, was established with the use of experimental observations. For this purpose, electromagnetic frequency soundings were carried out with the use of a "dry" dipole, grounded to crystalline rocks in the inner part of the isthmus between the Sredny and Kola Peninsulas, and a "wet" dipole, representing the "MHD-Khibiny" cable that has been immersed into opposite sea gulfs. The similar parameters of two measured geoelectrical sections were obtained after taking into account that only $20 \%$ of the total current of the MHD generator penetrates the earth by galvanical way and forms electric type fields [9]. This ratio was confirmed later by theoretical calculations and physical modeling [2].

\section{2. "Cold" Launches}

In Northern Norway, because of short distances between transmitter and receiver $(60-130 \mathrm{~km})$, EM measurements were performed in the "cold" mode with the use of station ERS-67 of 29-kW power mounted on the chassis of a ZIL-131 car and connected to the "Khibiny" circuit. A ballast of 10 Ohm resistivity has been connected in series to the feeding cable to supply to the concordance between the high internal resistivity of ERS-67 generator $(10 \mathrm{Ohm})$ and low total resistivity of cable and groundings of the circuit "Khibiny" (0.095 Ohm). As a result, only one-hundredth of the generator's power (about $290 \mathrm{~W}$ ) dissipated into the ground, but it was enough to make successful measurements in Northern Norway at a distance of up to $130 \mathrm{~km}$ from the source. There was almost no impulsive noise in the study area; the natural noise was low and homogenous ("white noise"). Thus, signal sampling of the current for 20 min duration enlarged the ratio "signal-noise" about 20 times, which proved sufficient to register the electric and magnetic components of the field [11]. 
The current was transmitted as bipolar square pulses with a frequency of $0.125 \mathrm{~Hz}$ and a strength close to 100 A from peak to peak. The sampling has been made by the first fronts of each half period of $4 \mathrm{~s}$ duration. The current variation $I(t)$ in the cable when switching on can be described by the formula:

$$
J(t)=J_{0} \cdot\left[1-\exp \left(-\frac{t}{\tau}\right)\right]
$$

where $J_{0}=\frac{V}{R}$-the totalDC current in the output of generator at $t \rightarrow \infty ; V$-voltage of the car generator; $R$ - the total active resistance of the cable and water groundings; $\tau=\frac{L}{R}$-the time constant; $L$-self-inductance of the "Khibiny" circuit, in Henri. $\tau$ corresponds to the time when the current $I(t)$ reaches $0.7 I_{o}$ after switching on the voltage. The self-induction $L$ of the circuit Khibiny depends on frequency (time in terms of time domain soundings). With decreasing frequency from $10 \mathrm{~Hz}$ to $0.1 \mathrm{~Hz}$, the induction $L$ of the circuit Khibiny increases from 18 to $80 \mathrm{mHn}$, based on experimental data [9]. This increase in $L$ can be explained by the increase in the length of the circuit "Khibiny" due to a spreading of the current in the sea $\left(J^{\text {sea }}\right)$ along the coastline and by offshore drifting (diffusion). The ballast resistance $R$, connected in series with the "Khibiny" feeding line, reduces the time constant from $1 \mathrm{~s}$ up to $0.01 \mathrm{~s}$. As a result, it makes the shape of the current fronts of "cold" appearsharper and more suitable for time domain measurements. Measurements were made in the time domain regime based on5components Ex, Ey, Hx, Hy, Hz.

\section{The Model of Current-Conducting Channel Detection}

The electromagnetic field of the "Khibiny" source is considered as a superposition of magnetic and electric sources. The magnetic source exists due to currents channeled through the cable to the sea $\left(J^{\text {sea }}\right)$. This current produces magnetic loops around the Sredny and Rybachy peninsulas. The electric source is exerted by galvanic currents dissipating into the ground through the sea bottom $\left(J^{\text {galv }}\right)$. By its nature, component $\mathrm{Hz}$ should reflect the form of MHD pulses, i.e., it should be unipolar (Figure 1c). All MHD pulses have been executed at the same positive polarity of the current, penetrating to the sea from the Motovsky gulf (Figure 1a). The positive polarity of the vertical component of the magnetic field complies with its penetration from the top to the down. In this case, by the low of the right screw, the magnetic field at the central parts of the Rybachy and Sredny peninsulas and at the most sea area should extend from bottom to top, i.e., in the negative direction. In the receiving points, situated outside the sea coastline (on the Kola peninsula), the magnetic field propagates in the direction from top to down, i.e., in the positive direction. The nature of negative signals $\mathrm{Hz}$ appearing in some receiving sites is connected with galvanic currents $\left(J^{\text {galv }}\right)$ flowing in current-conducting channels represented by sulfide- and carbon-bearing rocks, fracture zones, grounded power lines, railway lines, etc. In receiving points, situated near current-conducting channels, the superposition happens in magnetic fields produced by induction owing to currents flowing in the sea $\left(f^{\text {sea }}\right)$ and those produced by galvanic currents ( $g^{g a l v}$ ) leaking into the Earth's crust through the sea bottom (Figure 1a).

The synthetic sketch of superposition of magnetic fields produced by induction and galvanic sources in the "Khibiny" experiment is shown in Figure 2. 


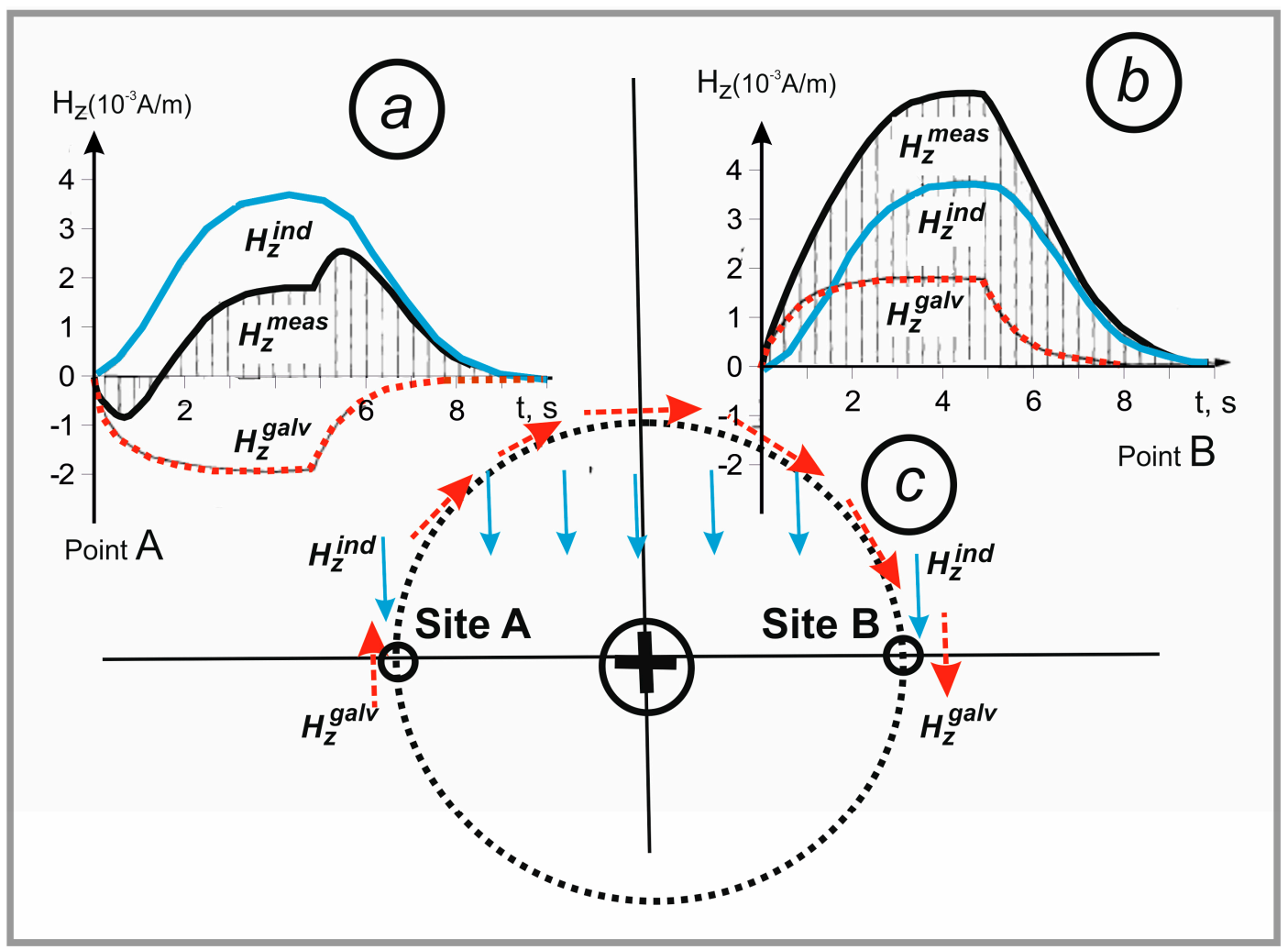

Figure 2. Scheme of magnetic fields, measured from MHD-installation "Khibiny" in opposite sides of the current-conducting channel. (a) Curves of the vertical magnetic field for the left site " $\mathrm{A}^{\prime}: \mathrm{H}_{z}^{\text {ind }}$ (blue)—induced by sea currents, $\mathrm{Hz}^{\text {galv }}$ (red, dashed)—based on galvanic currents in the ground and $H z^{\text {meas }}=H_{z}^{\text {ind }}+H z^{\text {galv }}$ (black, solid) measured magnetic field; (b) same for right site " $\mathrm{B}$ "; (c) vectors of magnetic field: $\mathrm{Hz}^{\text {galv }}$ from current " + ", flowing away from observer (dashed arrows) and $H_{z}^{\text {ind }}$ from distant currents in the sea (solid arrows).

In Figure 2, the registration of the vertical magnetic component $\mathrm{Hz}$ is presented on the example at sites A and B situated symmetrically on opposite sides regarding the current conductor of endless length. Sign " + " indicates that the current flows away from the observer. Curves and arrows $\mathrm{Hz}$ ind (Figure $2 \mathrm{a}-\mathrm{c}$ ) show the behavior of magnetic field produced by remote current streams in the sea. Since the velocity of current diffusion in the sea is low, the respective electromagnetic signals of the magnetic source have flat frames with a low-frequency range. They penetrate to the Earth's crust without responding to the heterogeneous electric conductivity of the upper Earth's crust. Therefore, graphs $\mathrm{Hz}^{\text {ind }}$ on opposite sides of the conductor (Figure 2a,b) are identical.

The amplitude of the vertical magnetic component produced by the current in the sea can be approximated by the formula for the stationary vertical magnetic dipole.

$$
H z^{\text {sea }}(t)=\frac{M}{4 \pi r^{3}},\left[\frac{A}{m}\right]
$$

where the magnetic moment of the source $M=J_{\text {sea }} \cdot \pi R^{2}, J_{\text {sea }}$ is thecurrent strength in the sea, $R$ is the radius of the magnetic loop in the sea (about $50 \mathrm{~km}$ ), and $r$ is the distance from the receiver to the center of the magnetic loop.

Curves $\mathrm{Hz}^{\text {galv }}$ (Figure 2a,b) reflect the behavior of the magnetic field produced by an endlessly long conductor with the current in the ground. The magnetic field of the galvanic nature has frames that are as steep as the current in the source. It also has different polarities on opposite sides of 
the current. The polarity (direction) of the magnetic field $H z^{g a l v}$ is defined by the right-hand rule. The amplitude of the field in the stationary state is found by Amper's law to be

$$
H z^{g a l v}(t)=\frac{J_{g a l v}(t)}{2 \pi \cdot r},\left[\frac{A}{m}\right] .
$$

The measured vertical magnetic component $(\mathrm{Hz}$ meas $)$ is defined as a sum of fields of the induction and galvanic origin:

$$
H z^{\text {meas }}(t)=H z^{\text {sea }}(t)+H z^{\text {galv }}(t) .
$$

Curves $\mathrm{Hz}^{\text {meas }}$ indicating the behavior of the measured (summarized) vertical magnetic field on opposite sides of the conductor have absolutely different-looking shapeson sites " $\mathrm{A}$ " and "B" (Figure 2). Their behavior, character and amplitude allow tracing the location of the current-conducting channel and its parameters. If we estimate the distance to the center of the current-conducting channel and the distance from it to the reference point, we can easily define the current strength of the galvanic origin in the conductor, using the equation

$$
\operatorname{Jtot}^{\text {galv }}=2 \pi \cdot r^{\text {galv }} \cdot \text { Htot }^{\text {galv }},[A] .
$$

\section{Results of Field Experiments}

The common scheme of the current-conducting channels'distribution on the Kola Peninsula obtained with the use of MHD-source "Khibiny" in the mode of "hot" pulsesis shown in Figure 3a.

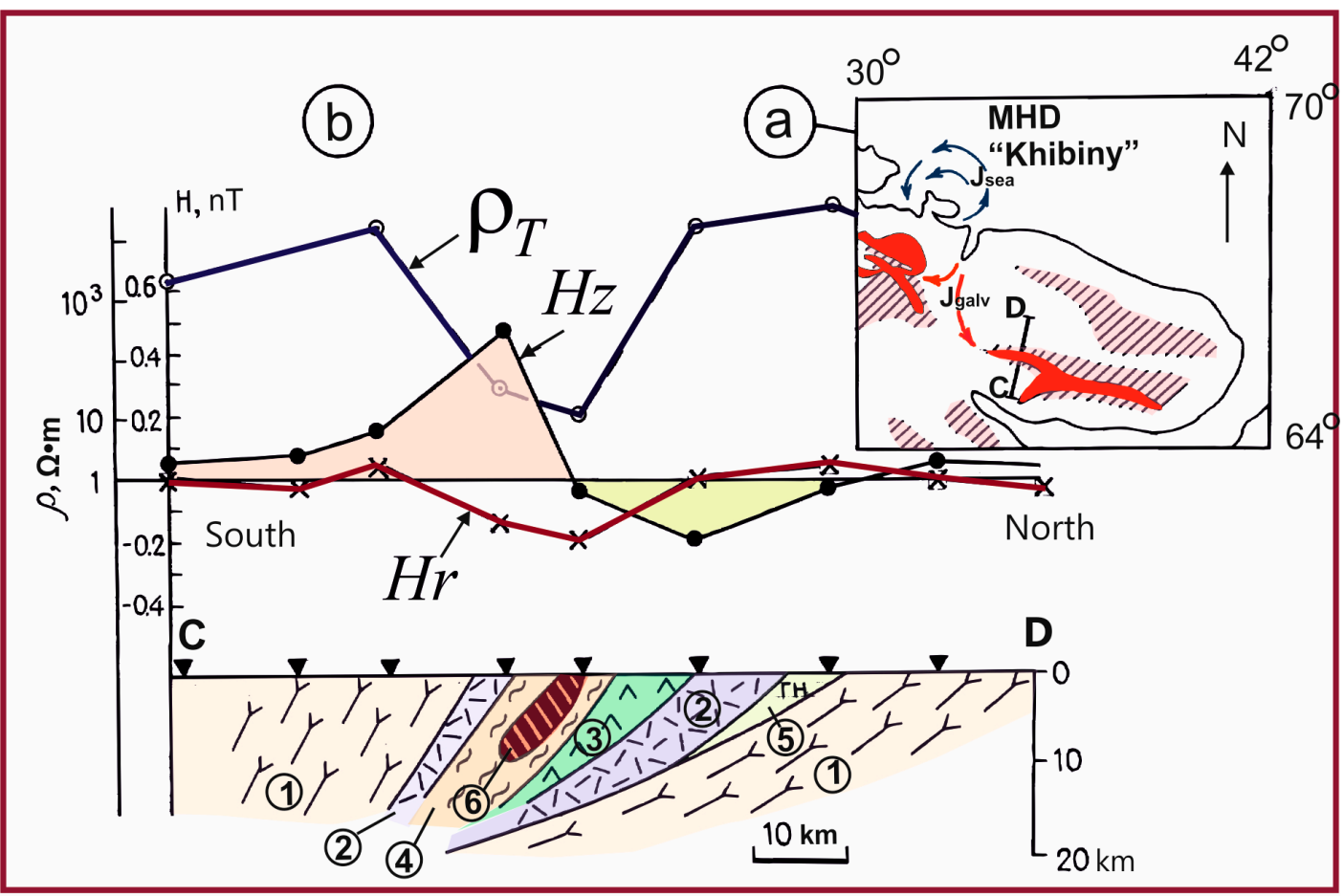

Figure 3. Example of current-conducting channels study on the Kola peninsula with the use of MHD-source "Khibiny" in the mode of "hot" pulses. (a) The view of conductive structures and MHD currents in the sea (blue arrows) and the Earth crust (red arrows); (b) current-conducting channel's study over the Imandra-Varzuga structure by profile CD. Legend (numerals in circles): 1-granite-gneiss; 2-volcanites; 3-effusives; 4-schists and volcanites of the Tominga Series; 5-gabbro-norites; 6 -location of the conductive channel

The direction of galvanic currents is shown by hatched (red) arrows that flow from the MHD-source "Khibiny" and then concentrate on conductive structures of the Pechenga-Alarechensky 
region (on the western part of the Kola peninsula) and on the Imandra-Varzuga structure (on the eastern part of the Kola peninsula). It is apparent that the in rocks of the Imandra-Varzuga and Pechenga-Alarechensky zones galvanic currents run in opposite directions. It is important evidence of their galvanic nature caused by conductive currents in the earth's crust. The galvanic current's intensity in the Pechenga conductive suites, which are located closer to MHD-source, is of $40 \mathrm{~A}$, and that of the Imandra-Varzuga zone is $12.5 \mathrm{~A}$. These values make up about one percent of current intensity of the MHD-generator, penetrating into the earth galvanically and amounting about of $4 \times 10^{3} \mathrm{~A}$. Nevertheless, that fact that the galvanic currents are found in the conducting geological structures is important to gain a better insight into the model of electric conductivity in the basement of the Baltic Shield. It is thus clear that, in the upper part of the earth's crust, in spite of the absence of the sedimentary deposits and high resistivity of the exposed crystalline rocks, there are channels for ultralow-frequency, virtually direct current running in the horizontal direction over hundreds of kilometers. A detailed scheme of a current-conducting channel study is presented in Figure $3 \mathrm{~b}$ in the example of measurements carried out along the profile $C D$, crossing the Imandra-Varzuga structure.

The Imandra-Varzuga is a riftogene structure composed of the Lower Proterozoic volcano-sedimentary rocks, which are similar by composition and structure to the Pechenga formation. It extends for $350 \mathrm{~km}$ in the latitudinal direction (Figure 3a). It contains 10-12 volcano-sedimentary layers, some of which include high carbon- and sulphide-bearing phyllite-like rocks (black schists), enriched in pyrite-pyrrhotite mineralization and widespread in the section of the Tominga Series, which is located in the central part of the profile CD (Figure 3b).

Results of current-conducting channel study in Figure $3 \mathrm{~b}$ are given by graphs of anomalous vertical magnetic component $H z^{\text {galv }}(t)$ (signed as $\mathrm{Hz}$ ), a module of the total horizontal magnetic field $H r$ and curve of apparent resistivity $\rho_{T}$, calculated by the total input impedance. The component $H z^{\text {galv }}(t)$ has been estimated using the Equation (6) by subtracting the regional magnetic field $\mathrm{Hz}^{\text {sea }}(t)$ produced by current loops in the sea from the measured field $\mathrm{Hz}^{\text {meas }}(t)$ :

$$
H z^{\text {galv }}(t)=H z^{\text {meas }}(t)-H z^{\text {sea }}(t)
$$

Values $H z^{\text {sea }}(t)$ are given by the Equation (2) for the field of the vertical magnetic dipole. Values of the total horizontal magnetic field module $\mathrm{Hr}$ have been compiled from measured data after extraction of the regional low-frequency trend. An apparent resistivity curve $\rho_{T}$ has been calculated for the period $T=1 \mathrm{~s}$ with the use of magnetotelluric Equation (7).

$$
\rho_{T}=0.127 T \cdot\left(Z_{t o t}\right)^{2},
$$

where the total (effective) impedance $Z_{t o t}=\frac{E r}{H r}$. $E r, H r$ are modules of the total horizontal electric and magnetic fields accordingly.

In the central part of profile $\mathrm{CD}$, electric and magnetic components manifest anomalous behavior. The vertical magnetic component $\mathrm{Hz}$, crossing the zero, has a negative sign at the north side from the current-conducting channel ( 6 on Figure $3 b$ ) anda positive sign at the south from conductive body. Horizontal magnetic field $\mathrm{Hr}$ has a negative sign over the anomalous body. All these features, if we compare them with Figure 2, denote that the anomalous current runs from the west to the eastwards in the graphitic schist of the Tominga series.

The quantitative 2D interpretation of the magnetic field (Figure 3a) points out the southern dipping of the conductive body and its continuation to the depth of about $10 \mathrm{~km}[9,12,13]$. This estimation agrees well with results of numerical modeling of MHD-signals using the technique of electromagnetic migration [14] and with results of magnetovariation profiling implemented at the western flank of Imandra-Varzuga structure, near to profile CD [15].

Results of the tracing of current-conducting channels on the western flank of the Pechenga structure are presentedin Figure 4c. The data processing procedure was the same as has been applied above for the Imandra-Varzuga structure (Figure 3b). Current-conducting channels on Figure 4c are 
shown by dashed lines. Channels, which are confidently identified in the field of the MHD installation "Khibiny", are shown by bold dashed lines. Weaker conductors, which are mainly fixed from results of electrical profiling with the method of internal sliding contact (MISC) [16], are shown by thinner dashed lines. From a comparison of Figures $3 b$ and $4 c$, we can notice sufficient difference in the behavior of magnetic fields. The vertical magnetic component $\mathrm{Hz}$ has a positive sign onthe northern side from the current-conducting channels anda negative sign at the south. Horizontal magnetic field $\mathrm{Hr}$ has a positive sign over the conductive channels. All these features point out that the anomalous current in the West Pechenga runs from the east side to the west, i.e., in opposite directions compared to the Imandra-Varzuga structure that has been shown above in Figure $3 \mathrm{~b}$.

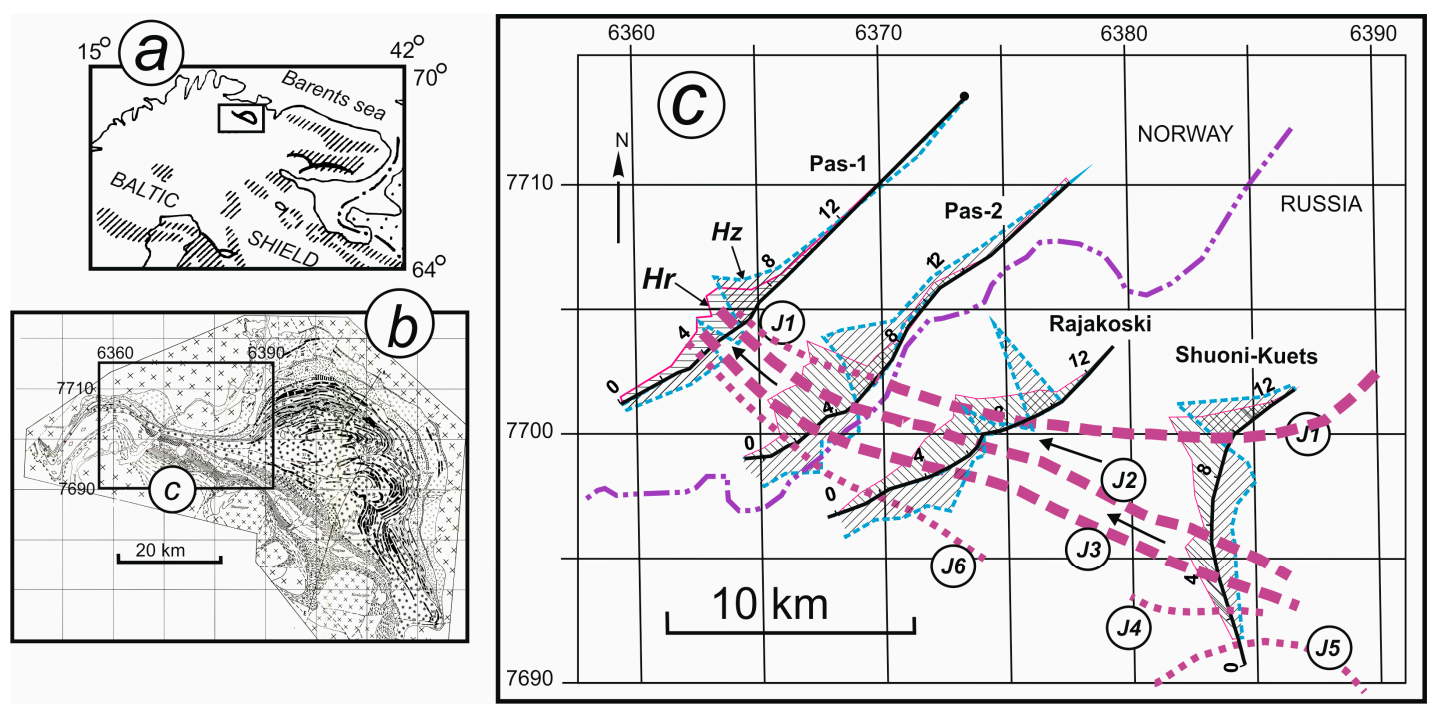

Figure 4. Results of the west Pechenga study in the field of MHD-installation "Khibiny". (a) Thecommon view of the study area; (b) geology of Pechenga structure by [17]; (c) current-conducting channels (J1-J6) of the west Pechenga and graphs of the anomalous magnetic field of the source "Khibiny" - vertical, Hz and horizontal, Hr. Black arrows show the direction of current flow in conductive channels.

Figure $4 \mathrm{a}, \mathrm{b}$ point out in an uninterrupted continuation of current-conducting channels and geological formations of the western flank of the Pechenga structure. Channel J1 coinciding with $\mathrm{Cu}-\mathrm{Ni}$ productive Pil'gujarvisuite creates the most intensive anomalous effect on the regional profile Shuoni-Kuets. Going further west, the intensity of the anomalous field above the productive suite decreases from one profile to another. The anomalous effect fades on profile Pas-1. Compared to results of MISC electrical profiling, this study suggests that near the profile Pas-1 the thickness of the conductive body equated to the productive suite decreases to $20-30 \mathrm{~m}$. Its longitudinal conductivity accordingly decreases from 1000 S on the east profile Shuoni-Kuets to 3-5 S on the western profile Pas-1.

Geological interpretation of results is shown in Figure 5 on the base of the map from [17]. As noted above the $\mathrm{Cu}-\mathrm{Ni}$ productive stratum, the fourth sedimentary horizon of Pechenga is most effectively detected on Shuoni-Kuets profile (channel J1). Further to the west, the anomalous effect from channel J1 gradually fades. At the interval between profiles PAS-1 and PAS-2, it can be traced only by electrical profiling results. 


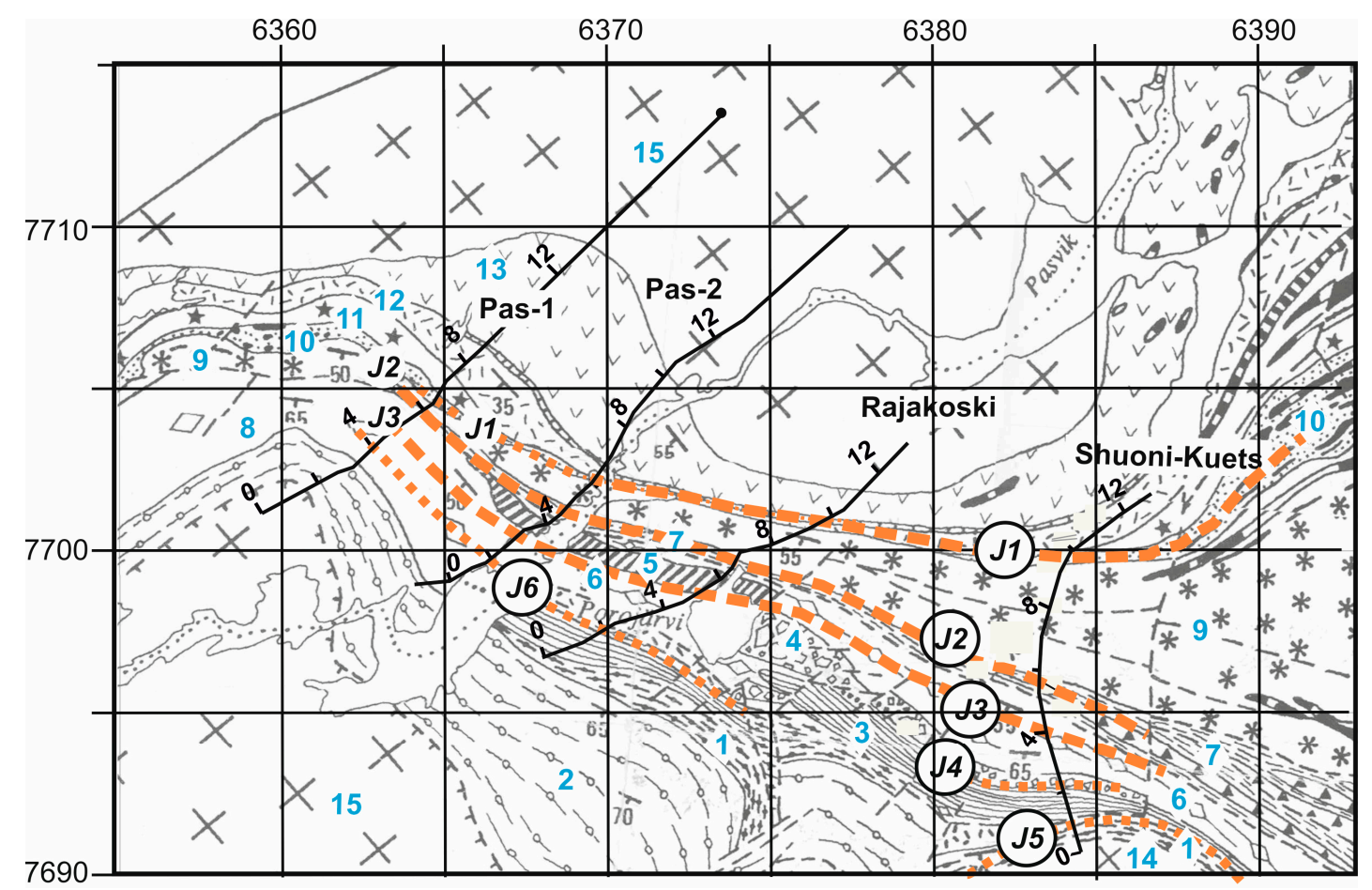

Figure 5. Location of conductive layers J1-J6 on the geological map by V.A. Melezhik [17]. Legend shown by blue figures: South Pechenga (1-8): 1-Pestchanoe Lake (toleit-basalt); 2-Talja (siltstone); 3-Kasesjoki (andesitic sandstone); 4-Kaplya (tuff, andesite); 5-Faregmo (andesit lava and tuff); 6-Bragino (tuffit, andesite); 7-Kallojavr, Porjitash ( $\mathrm{C}_{\text {org }}$ and sulfide-rich sandstone, basalt, andesite); 8-Langvannet, Porojarvi ( $C_{\text {org }}$ and sulfide-rich sandstone, basalt, andesite).North Pechenga (9-13): 9-Pil'gujarvi volcanic (4th diabas, basalt layer); 10-Pil'gujarvi sedimantari (4th sedimentary layer, $\mathrm{C}_{\text {org }}$ and sulfide-rich sandstone); 11-Kolasjoki (3rd diabas, basalt layer); 12-Kuetsjarvi (2nd diabas, basalt layer); 13-Ahmalahti (1st diabas, basalt layer); 14-Shuonijarvisinorogenic Granite Archaean Basement (2.9-2.5 Ga): 15-tonalit, granite, amfibolite.

Channels J2 and J3 create much stronger anomalous effects. Channel J2 is connected with the Kallojavr-Porjitash formation, composed of sandstones (rich of Corg and sulphides) with interlayers of basalts and andesites. Channel $J 3$ has a rather complex structure. In the east, at the intersection with the Shooni-Kuets profile, it coincides with Bragino formation, composed of tuffs and andesites, but registered high electrical conductivity does not cause doubt in the presence of electronically-conductiveminerals like sulphides (pyrite, pyrthotite), carbon rocks, and graphite in its composition.

Further in the west, channel $J 3$ in Figure 5 becomes as a part of the Langvannet-Porojarvi formation, rich in sulfides and carbonaceous schists with interbeds of andesites and basalts. The total longitudinal conductivity of channels $J 2$ and $J 3$ in the region of the profiles Pas- 1 and Pas- 2 is about $2000 \mathrm{~S}$, whereas in the channel $J 1$ (productive stratum), this value is a thousand times less and is in the range of 2-3 S.

In Figure 6, results of numerical 2D modeling are presented altogether with graphs of horizontal and vertical magnetic field induced by "Khibiny" dipole and with resistivity curves of DC electrical profiling. 

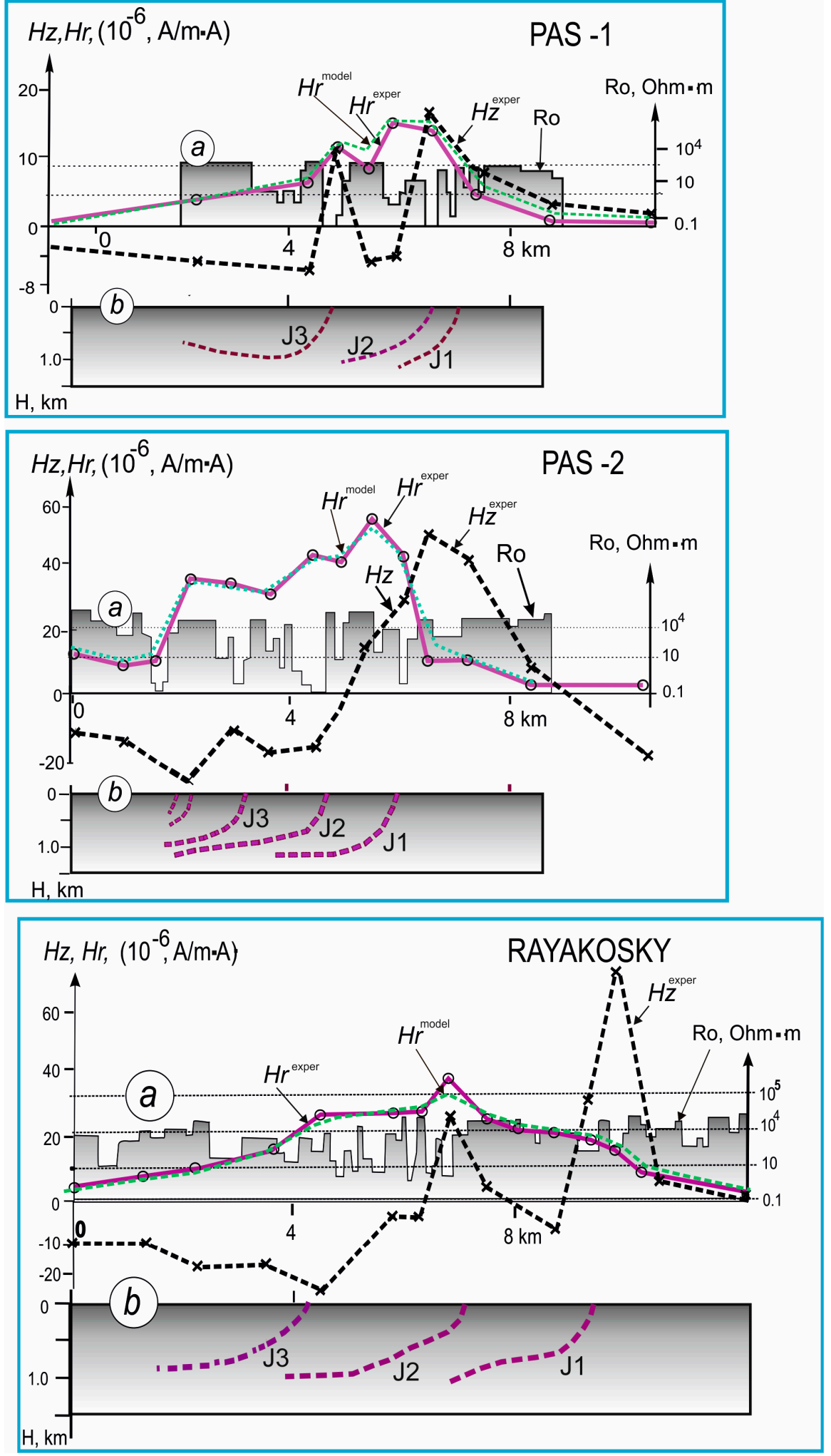

Figure 6. Results of the study of conductive layers of the Pechenga structure's Western flank by profiles PAS-1, PAS-2 andRayakosky. Location of profilesis shown in Figures 4 and 5. Letters in circles: $a$ - graphs of resistivity Ro from DC electrical profiling and graphs of measured horizontal $\mathrm{Hr}^{\text {meas }}$ andvertical $\mathrm{Hz}^{\text {meas }}$ magnetic field from MHD "Khibiny" dipole and modeled horizontal magnetic field $\mathrm{Hr}^{\text {model }} ; b$ - the deep sections of conductive layers from the results of 2D digital modeling. J1, J2 and J3-current conductive channels shown on Figures 5 and 6. 
The 2D numerical modeling has been performed to estimate the bed position and the conductor length to the depth. The special "Magnet-2" program has been elaborated for this purpose by V.E. Asming [10]. This program allows detecting the magnetic field by summing a certain set of endlessly long horizontal current lines (DC) in a free half-space, ignoring any impact of extrinsic currents. An interpreter device detects the amount and location of currentlines in the 2D model on-line. An optimal solution of the inverse problem is solved automatically when model and experimental data are adjusted with the least-square method.

Results of DC profiling are obtained with the use of Method of Internal Sliding Contact (MISC), which combines sounding and profiling techniques [16]. Therefore, resulting resistivity curves present $1 \mathrm{D}$ inversion data and reflect the resistivity of crystalline rocks under overburden at a depth of about $20 \mathrm{~m}$. Results of 2D modeling of the data from the study of current-conducting channels in the west flank of the Pechenga structure with the use of MHD-installation "Khibiny" make it possible to get an idea of the behavior of conductive horizons to the depth. Against the background of a general narrowing of the thickness of the Pechenga volcanic-sedimentary strata as they move westward (Figures 4 and 5), the conductor length is also reduced to a depth of 1-1.5 km. At the same time, the southern fall of rocks remains, subvertical near the surface of the day and flattening with depth. It is important to note from Figure 6 that the intensity of the anomalous magnetic field (as horizontal $\mathrm{Hr}$ so vertical $\mathrm{Hz}$ ) sharply (nearly twice) decreased in the profile PAS-1 compared to PAS-2. It can be explained by the sharp bending of conducting layers on the westward (Figure 5) and by the changing of the geological structure from 2D to the 3D model.

\section{Discussion}

Results presented in the article of conductive horizons study of the Pechenga structure in the field of MHD-installation "Khibiny" are based on an informal, phenomenological approach. This is due, first of all, to the fact that parameters of the MHD source "Khibiny" do not fall under a well-defined physical-mathematical model. This unique transmitter consists of two types of sources-the magnetic (induction) one created by currents flowing in the Barents sea and the electric (galvanic) one that happened due to currents leaking to the ground from the sea gulfs' bottom. The intensity and correlation of these currents are established empirically on experimental measurements of electric and magnetic components of the field generated by MHD-source [9]. The phenomenological approach means the application of the strict well-known physical laws to study the heterogeneous media with the uncertain distribution of the current parameters. The current-conducting channels' existence and methods for their quantitative interpretation were developed with the use of experimental measurements and the data treatment experience in similar situations, for example, Viese vector study in the magnetovariation method [18]. Along with this, we note that the phenomenological approach is widespread in the practice of many other geophysical methods, and it brings its tangible fruits. In particular, the physical-mathematical models of the induced polarization method and the method of induction time domain sounding in the near-field zone are based on the phenomenological approach [19,20]. An important result of the phenomenological interpretation of the "Khibiny" experiment is connected with the finding that conductive channels are of limited penetration to the depth-from a few to $5-10 \mathrm{~km}$ and with conclusion about the concentration of galvanic currents in the upper film of the crystalline Earth's crust of about $10 \mathrm{~km}$ thickness [21]. One of the most powerful current-conducting channels (with a thickness of up to $10-12 \mathrm{~km}$ and a length of up to $80 \mathrm{~km}$ ) is connected with the Cu-Ni productive formation Pil'gujarvi (the fourth sedimentary horizon) of the Pechenga structure. Within the framework of the "Northern Region" project, special observations were made to trace the continuation of the $\mathrm{Cu}-\mathrm{Ni}$ productive strata Pil'gujarvi of the Pechenga structure to the territory of Northern Norway. Results of these works showed that the thickness of Pil'gujarvi $\mathrm{Cu}-\mathrm{Ni}$ productive strata on the territory of Northern Norway is reduced to 20-30 m and accordingly decreases by approximately three orders of magnitude (from $2000 \mathrm{~S}$ to $2-3 \mathrm{~S}$ ) in its longitudinal conductivity. At the same time, the conducting horizons of the southern part of the Pechenga structure 
(Kallojavr-Porjitash, Bragino, Langvannet-Porojarvi), distinguished by low prospects for the discovery of copper-nickel deposits, are traced in Norway almost without a reduction in thickness (reaching $1-2 \mathrm{~km}$ ) and in conductivity (reaching $2000 \mathrm{~S}$ ). Thus, the results of the work with the MHD installation "Khibiny" testifies to the actual wedging of the Cu-Ni productive strata of the Pechenga structure in Northern Norway.

The novelty of the work, in comparison with previous publications [10,11], is based on a more complete description of technique of the work using not only "cold", but also "hot" launches of the MHD installation "Khibiny". The description is made for the entire territory of the Kola Peninsula. This allows us to more fully and visually assess the physical meaning of the original method of conductive channels tracing by means of dividing the field of the Khibiny MHD source into galvanic and induction modes. An important element of novelty is associated with a more rigorous description of geological results based on a rectangular Gauss-Kruger grid. This made it possible to make a more concrete and substantiated conclusion about the pinching out of the Pil'guyarvi ( $\mathrm{Cu}-\mathrm{Ni}$ productive) strata of the Pechenga on the territory of Northern Norway and corresponding decrease of perspectives on the search of copper-nickel deposits. Finally, the paper emphasizes the connection of the obtained results of current conductive channels study with modern concepts of the two-layered structure of the continental Earth's crust with its division into the upper, brittle heterogeneous part, about $10 \mathrm{~km}$ thick, and a lower ductile homogeneous part that extends to the Moho border and deeper [21].

Funding: This work was supported by the project of the Russian-Norwegian cooperation "Northern Region", the Russian Fund for Basic Research (RFBR), grant No 18-05-00528 (methods) and partly by the support of the State Mission, GI KSC RAS, the subject of research 0226-2019-0052 (interpretation).

Acknowledgments: The author is deeply grateful to colleagues whose participation in field research and data processing has been reflected in a number of joint articles on this topic: A.D. Tokarev, Yu.A. Vinogradov, T.G. Korotkova, V.E. Asming, A.N. Shevtsov, N.A. Ochkur, A.G. Yampolsky, O.B. Lile, Yan Ronning, H. Moxness. The author dedicates this work to the bright memory of Academician Felix Mitrofanov with gratitude for the support and high appreciation ofresults. The author is deeply grateful to the anonymous reviewers for the careful review of the manuscript and for the many comments that contributed to a more accurate and complete presentation of the material.

Conflicts of Interest: The authors declare no conflict of interest.

\section{References}

1. Velikhov, E.P.; Volkov, Y.M. Prospects for the development of pulsed MHD—Energy and its application in geology and geophysics. In Deep Electromagnetic Soundings Using Pulse MHD Generators; The Kol'sky Philial Akademii Nauk of USSR (KFAN SSSR): Apatity, Russia, 1982; pp. 5-25. (In Russian)

2. Velikhov, E.P. (Ed.) Geoelectrical Investigations with the Powerful Source of Current on the Baltic Shield; Nauka: Moscow, Russia, 1989; p. 272. (In Russian)

3. Zhamaletdinov, A.A. (Ed.) Theory and Method of Deep Electromagnetic Sounding on Crystalline Shields; Devoted to MHD Soundings; Kola Science Center RAS: Apatity, Russia, 2006; Volume 1, p. 240. (In Russian)

4. Velikhov, E.P.; Panchenko, V.P. Large-scale geophysical surveys of the earth's crust using high-power electromagnetic pulses. In Active Geophysical Monitoring; Kasahara, J., Korneev, V., Zhdanov, M., Eds.; Elsevier: Amsterdam, The Netherlands, 2010; pp. 29-52.

5. Zhamaletdinov, A.A. «Khibiny» MHD Experiment: The 30th Anniversary. Izv. Phys. Solid Earth 2005, 41, 737-742.

6. Smol'kin, V.F.; Skuf'in, P.K.; Mokrousov, V.A. Stratigraphic Position, Geochemistry and Genesis of Volcanic Association of the Early Proterozoic Pechenga Area. In Geology of the Eastern Finnmark-Western Kola Peninsul; Region, O., Nordgulen, D., Eds.; Special Publication No.7; Geolodical Survey of Norvay: Trondheim, Norway, 1995; pp. 93-110.

7. Zagorodny, V.G.; Mirskaya, D.; Suslova, S.N. Geological Structure of the Pechenga Sedimentary-volcanic Series; Nauka: Moscow-Leningrad, Russia, 1964; p. 207. (In Russian)

8. Gorbunov, G.I. Geology and Genesis of Sulphide Copper-Nickel Deposits of Pechenga; Nedra: Moscow, Russia, 1968; p. 352. (In Russian) 
9. Zhamaletdinov, A.A. The Model of the Lithosphere Electro-Conductivity from the Results of Researches with Controlled Sources; Nauka: Leningrad, Russia, 1990; p. 156. (In Russian)

10. Zhamaletdinov, A.A.; Tokarev, A.D.; Vinogradov, Y.N.; Asming, V.E.; Otchkur, N.A.; Ronning, I.S.; Lile, O.B. Deep geoelectrical studies in the Finnmark and the Pechenga area by means of the "Khibiny" source. Phys. Earth Planet. Int. 1993, 81, 277-287. [CrossRef]

11. Zhamaletdinov, A.A.; Ronning, J.S.; Lile, O.B.; Tokarev, A.D.; Smolkin, V.F.; Vinogradov, Y.A. Geoelectrical Investigation with the 'Khibiny' Source in the Pechenga-Pasvik Area. In Geology of the Eastern Finnmark-Western Kola Peninsula; Region, D., Nordgulen, O., Eds.; Special Publication No.7; Geolodical Survey of Norvay: Trondheim, Norway, 1995; pp. 339-347. ISBN 82-7385-158-3.

12. Velikhov, E.P.; Zhamaletdinov, A.A.; Zhdanov, M.S. The Khibiny experiment. Earth Planets 1989, 15, $12-18$. (In Russian)

13. Kirillov, S.K.; Osipenko, L.G. Study of the Imandra-Varzuga Conductive Zone (Kola Peninsula) with the Use of MHD Generator. In Crustal Anomalies of Electrical Conductivity; Nauka: Leningrad, Russia, 1984; pp. 79-86. (In Russian)

14. Zhdanov, M.S.; Frenkel, M.A. Migration of Electromagnetic Fields in Solving Inverse Problems of Geoelectrics; Moscow, Doklady Akademii Nauk (DAN USSR): Moscow, Russia, 1983; Volume 271, pp. 589-594.

15. Zhamaletdinov, A.A.; Kulik, S.N.; Pavlovsky, V.I.; Rokityansky, I.I.; Tanatchev, G.S. Anomaly of short-period geomagnetic variations over the Imandra-Varzuga structure (Kola Peninsula). Geofiz. J. 1980, 2, 91-96. (In Russian)

16. Zhamaletdinov, A.A.; Ronning, J.S.; Vinogradov, Y.A.B. Electrical profiling by the MISC and Slingram methods in the Pechenga-Pasvik area. In Geology of the Eastern Finnmark-Western Kola Peninsula Region; Roberts, D., Nordgulen, O., Eds.; Special Publication No.7; Geolodical Survey of Norvay: Trondheim, Norway, 1995; pp. 333-338.

17. Melezhik, V. Geological Map of Pechenga. In Geology of the Eastern Finnmark-Western Kola Peninsula Region; Roberts, D., Nordgulen, O., Eds.; Special Publication No.7; Geolodical Survey of Norvay: Trondheim, Norway, 1995; (map is enclosed as attachment).

18. Rokitjansky, I.I. Inductive soundings of the Earth; Naukova Dumka: Kyiv, Ukraine, 1981; p. 296. (In Russian)

19. Komarov, V.A. Electrical Exploration by Induced Polarization; Nedra: Moscow, Russia, 1980; p. 391. (In Russian)

20. Kamenetsky, F.M. Electromagnetic Geophysical Studies by the Method of Transient Processes; Moscow, Geos: Moscow, Russia, 1997; p. 162. (In Russian)

21. Zhamaletdinov, A.A. The Nature of the Conrad Discontinuity with Respect to the Results of Kola Superdeep Wel Drilling and the Data of a Deep Geoelectrical Survey. Dokl. Earth Sci. 2014, 455 Pt 1, 350-354. [CrossRef] 